\title{
EDITORIALS
}

\section{Safe, High Quality Care Around the Clock: What will it Take to Get us There?}

\author{
Michelle Mourad, $M D^{7}$ and Josh Adler, $M D^{2}$ \\ 'Department of Medicine, Division of Hospital Medicine, University of California San Francisco, San Francisco, CA, USA; ${ }^{2}$ Department of \\ Medicine, Division of General Internal Medicine, University of California San Francisco, San Francisco, CA, USA.
}

J Gen Intern Med 26(9):948-50

DOI: $10.1007 / \mathrm{s} 11606-011-1795-5$

(c) Society of General Internal Medicine 2011

I n Crossing the Quality Chasm ${ }^{1}$ the Institute of Medicine called for improvements in six dimensions of health care quality: safety, effectiveness, patient-centeredness, timeliness, efficiency and equity. The report suggests that these improvements cannot be achieved within the constraints of the existing system of care. In this issue of the Journal, Wong et al., make a similar argument, proposing that our current "office hours" system of hospital care is incapable of providing high quality health care on nights and weekends. ${ }^{2}$

The authors concerns over temporal care disparities are warranted. The evidence provided for mortality differences in weekend admission for acute myocardial infarction(AMI), upper gastrointestinal bleed(UGIB), acute pulmonary embolus(PE) and pneumonia make a compelling case for reforming the way care is provided. ${ }^{3-6}$ Reports of less aggressive care during off hours, higher rates of surgical complications and medical errors as well as higher mortality from cardiac arrest only serve to strengthen their assertion. ${ }^{7,8}$ It is unacceptable for a patient's experience or outcome to differ by time of day or day of week. The challenge lies in identifying the most effective and efficient means to eliminate these disparities.

\section{NIGHTS VERSUS WEEKENDS}

While the temptation may be to implicate night and weekend care equally in outcome disparities, the evidence linking weekend admissions to poorer outcomes is more robust than that for nighttime admissions. In fact, multiple studies describing care differences on weekends found no differences in outcomes during nights. A landmark article on mortality differences in ICU admissions found significant differences in mortality during weekends, but no difference by time of day ( $21.4 \%$ daytime mortality, $20.8 \%$ nighttime). ${ }^{9}$ Studies that evaluated time of admission and mortality for specific diagnoses: AMI, PE, and UGIB found increased mortality with weekend admissions, but no differences overnight. $^{3-6}$ Thus, our highest priority should be improving care on weekends.

Published online July 13, 2011

\section{Are We Right to Focus on Staffing?}

While it is reasonable to presume that efforts to make the organizational structure of hospitals homogeneous during weekdays, nights, and weekends will have a favorable impact on patient outcomes, the exact mix of reforms needed to equalize outcomes remains unknown. A commonly implicated reason for temporal care disparities is differences in staffing on nights and weekends, with most studies focusing on nursing. The data linking nurse staffing levels to patient outcomes is mounting. In the most definitive study demonstrating this relationship, Needleman and colleagues evaluated nurse staffing levels within a single hospital over time. Patients who were on a unit during a single understaffed shift suffered a $2 \%$ increase in mortality. ${ }^{10}$ On the other hand, state mandated increases in nurse staffing in California have resulted in a $17.5 \%$ decrease in the number of patients per nurse but did not reduce the of incidence of falls, the prevalence of hospital-acquired pressure ulcers or restraint use in medical-surgical units. ${ }^{11}$

Missing from the discussion is a clear understanding of typical staffing levels of various health professionals on weekends and nights versus weekdays. A key question is: Are nurse staffing ratios truly lower on weekends or on nights, and can differences be correlated with the observed differences in outcomes during these times? In the report by Needleman et al., day and evening shifts were more likely to be below target staffing than night shifts. ${ }^{9}$ Fifteen states have legislation that either guides or mandates levels of nurse staffing. In California, the minimum staffing levels for direct care nurses are mandated and thus must be consistent on weekends and nights, None of the cited studies demonstrating care disparities on nights and weekends were able to correlate outcome differences to staffing levels, whether for nurses or physician providers. ${ }^{3-6,9}$

Pharmacists and therapists have been shown to improve care as part of multidisciplinary care teams, ${ }^{12-16}$ though a relationship between ancillary staffing levels and patient outcomes has not been well studied. Other hospital personnel critical to the delivery of care such as radiology technicians may be more lightly staffed on weekends and nights, potentially delaying needed imaging and increasing the length of hospital stay. ${ }^{17,18}$ Whether these staffing differences are associated with poorer patient outcomes or simply the loss of efficiency is unknown. Also unknown, is the effect of specialty availability at smaller hospitals and emergency departments on patient outcomes. In one recent survey of emergency departments in California, the absence of readily accessible specialty consultation was associated with a significantly greater number of transfers, but subsequent outcomes were not reported. ${ }^{19}$ Studies in AMI 
patients suggest that with a robust transfer network, quality of care can be maintained. ${ }^{20}$

\section{Staffing Mix, Skill Level, Handoffs and Aggressiveness of Care}

Addressing staffing levels alone is unlikely to be sufficient in improving care. Increased emphasis should be placed on skill mix and experience of practitioners in the hospital. The literature demonstrates a clear and consistent association between skill mix and mortality, both for nurses ${ }^{21}$ and for other health care professionals. ${ }^{22}$ A richer skill mix and years of nursing experience are associated with lower mortality rates as well as a decreased number of infections, falls, decubitus ulcers and medication errors. ${ }^{21,23,24}$ Furthermore, there are likely to be fewer nursing supervisors and nurse specialists working at night and on weekends which may contribute to disparities in care. ${ }^{25}$

With the dramatic growth of ICU care, the effect of physician skill mix also deserves more consideration. Many studies have focused on the effects of intensivist staffing in the ICU. The largest systematic review demonstrated mandatory intensivist involvement was associated with lower ICU and hospital mortality and reduced ICU and hospital length of stay compared with no intensivist or elective intensivist consultation. ${ }^{26}$

Similarly, resident physicians who work weekends in the ED and in medical-surgical units may have less supervision than during the weekdays, which has been shown to affect patient care. ${ }^{27,28}$ On weekends physicians are more likely to "cover" for colleagues and have less comprehensive knowledge of the patients they are caring for, with more frequent handoffs in care. ${ }^{29,30}$ Poor quality and/or frequent handoffs between physicians have been linked to adverse events. ${ }^{29,30}$ The degree of expertise or experience may also be linked to the level aggressiveness of care provided on weekends versus weekdays. Differences in outcomes for acute MI on weekends were associated with less frequent use of invasive cardiac procedures and poorer outcomes. ${ }^{3}$

\section{Increased Staffing, Skill Mix and Costs}

Studies demonstrate that cost savings from preventing adverse events and reducing length of stay could pay for staffing reforms. ${ }^{31}$ However, the exact staffing formula needed to eliminate weekend disparities is unclear, making accurate cost determinations difficult. There are a number of encouraging studies in ICUs that have demonstrated staffing increases can be cost neutral when certain adverse event rates are reduced, ${ }^{32-36}$ while others have demonstrated a net increase in costs with the addition of lower-level providers. ${ }^{37}$

\section{Where do we Go from Here?}

Poorer outcomes for hospitalized patients on weekends compared to weekdays are indisputable and indefensible. Wong and colleagues have offered an important challenge to health policy makers, hospitals and providers to institute reforms. A focus on staffing levels is justified but likely not sufficient to address care disparities on weekends. Attention to skill mix, provider experience, supervision for resident physicians and other trainees, and improved quality and coordination of hand offs are necessary to make a demonstrable improvement in weekend patient outcomes. In this era of significant and increasing downward cost pressure on hospitals, mandatory increases in staffing levels will be difficult to implement. Targeted and evidence-based interventions, however, may be more feasible to pursue. Intensivist involvement in all ICU admissions, standardized high quality handoffs, and increased resident/trainee supervision on weekends/nights should be encouraged, if not required. Further research is needed to clarify whether staffing levels and skill mix are indeed the sources of outcome differences during off hours, and if so, for which health professionals. This information can then guide specific and targeted recommendations for reforms. Wong and colleagues propose that the equal outcomes seen with stroke and trauma teams demonstrate the benefits of ensuring the availability of "uniform, formalized and dependable" resources and standardized approaches to care for specific diagnoses. Similar models may have salutary impact on other high acuity diagnoses such as AMI, PE, UGIB and sepsis. Implementation of these models may be particularly challenging for smaller and more rural hospitals. Instead a focus on forming partnerships for rapid transfer to larger institutions may be a more efficient and less costly approach to improving outcomes on weekends and nights.

\section{CONCLUSIONS}

As Wong and his colleagues point out, research on care disparities is becoming increasingly common, and we must translate this existing knowledge into action. Changes should be guided by evidence that reveals the specific causes of outcome differences so that reforms may be efficient and not excessively costly. Ensuring uniform patient outcomes and experiences regardless of the time or day will certainly be of benefit to patients and is central to the responsibility of the healthcare delivery system in achieving the IOM aims for quality care.

Funding Sources: No funding sources, grants, or other financial support.

Corresponding Author: Michelle Mourad, MD; Department of Medicine, Division of Hospital Medicine, University of California San Francisco, 505 Parnassus Ave, M1287, Box 0131, San Francisco, CA 94143, USA (e-mail: Michelle.Mourad@ucsf.edu).

\section{REFERENCES}

1. Institute of Medicine Crossing the quality chasm: a new health system for the twenty-first century. Washington: National Academy Press; 2001.

2. Wong HJ, Morra D. Excellent hospital care for all: open and operating 24/7. J Gen Int Med. 2011: doi:10.1007/s11606-011-1715-8.

3. Kostis WJ, Demissie K, Marcella SW, et al. Weekend versus weekday admission and mortality from myocardial infarction. N Engl J Med. 2007;356(11):1099-109.

4. Shaheen AA, Kaplan GG, Myers RP. Weekend versus weekday admission and mortality from gastrointestinal hemorrhage caused by peptic ulcer disease. Clin Gastroenterol Hepatol. 2009;7(3):303-10. 
5. Ananthakrishnan AN, McGinley EL, Saeian K. Outcomes of weekend admissions for upper gastrointestinal hemorrhage: a nationwide analysis. Clin Gastroenterol Hepatol. 2009;7(3):296-302e1.

6. Aujesky D, Jimenez D, Mor MK, Geng M, Fine MJ, Ibrahim SA. Weekend versus weekday admission and mortality after acute pulmonary embolism. Circulation. 2009;119(7):962-8.

7. Bendavid E, Kaganova Y, Needleman J, Gruenberg L, Weissman JS. Complication rates on weekends and weekdays in US hospitals. Am J Med. 2007;120(5):422-8.

8. Peberdy MA, Ornato JP, Larkin GL, et al. Survival from in-hospital cardiac arrest during nights and weekends. JAMA. 2008;299(7):785-92.

9. Cavallazzi R, Marik PE, Hirani A, Pachinburavan M, Vasu TS, Leiby BE. Association between time of admission to the ICU and mortality: a systematic review and metaanalysis. Chest. 2010;138(1):68-75.

10. Needleman J, Buerhaus P, Pankratz VS, Leibson CL, Stevens SR, Harris M. Nurse staffing and inpatient hospital mortality. N Engl J Med. 2011;364(11):1037-45.

11. Donaldson $\mathbf{N}$, Shapiro S. Impact of California mandated acute care hospital nurse staffing ratios: a literature synthesis. Policy Polit Nurs Pract. 2010;11(3):184-201.

12. Karapinar-Carkit F, Borgsteede SD, Zoer J, et al. The effect of the $\mathrm{COACH}$ program (continuity of appropriate pharmacotherapy, patient counselling and information transfer in healthcare) on readmission rates in a multicultural population of internal medicine patients. BMC Health Serv Res. 2010;10:39.

13. Harbrecht BG, Delgado E, Tuttle RP, Cohen-Melamed MH, Saul MI, Valenta CA. Improved outcomes with routine respiratory therapist evaluation of non-intensive-care-unit surgery patients. Respir Care. 2009;54(7):861-7.

14. Netzer G, Liu X, Shanholtz C, Harris A, Verceles A, Iwashyna TJ. Decreased mortality resulting from a multicomponent intervention in a tertiary care medical intensive care unit. Crit Care Med. 2011;39(2):284-93.

15. Kim MM, Barnato AE, Angus DC, Fleisher LA, Kahn JM. The effect of multidisciplinary care teams on intensive care unit mortality. Arch Intern Med. 2010;170(4):369-76

16. Hoffmann T, Tornatore G. Early physical and occupational therapy in mechanically ventilated, critically ill patients resulted in better functional outcomes at hospital discharge. Aust Occup Ther J. 2009;56(6):438-9.

17. Conti CR. Restricted weekend services result in delays in discharges from hospital. Clin Cardiol. 2003;26(1): 1 .

18. Varnava AM, Sedgwick JE, Deaner A, Ranjadayalan K, Timmis AD. Restricted weekend service inappropriately delays discharge after acute myocardial infarction. Heart. 2002;87(3):216-9.

19. Menchine MD, Baraff $\mathbf{L} \mathbf{J}$. On-call specialists and higher level of care transfers in california emergency departments. Acad Emerg Med. 2008;15(4):329-36.

20. Blankenship JC, Scott TD, Skelding KA, et al. Door-to-balloon times under 90 min can be routinely achieved for patients transferred for STsegment elevation myocardial infarction percutaneous coronary intervention in a rural setting. J Am Coll Cardiol. 2011;57(3):272-9.
21. Tourangeau AE, Giovannetti P, Tu JV, Wood M. Nursing-related determinants of 30-day mortality for hospitalized patients. Can J Nurs Res. 2002;33(4):71-88.

22. Bond CA, Raehl CL, Pitterle ME, Franke T. Health care professional staffing, hospital characteristics, and hospital mortality rates. Pharmacotherapy. 1999;19(2):130-8.

23. Patrician PA, Loan L, McCarthy M, et al. The association of shift-level nurse staffing with adverse patient events. J Nurs Adm. 2011;41 (2):64-70.

24. Blegen MA, Goode CJ, Spetz J, Vaughn T, Park SH. Nurse staffing effects on patient outcomes: safety-net and non-safety-net hospitals. Med Care. 2011;49(4):406-14.

25. Hamilton P, Eschiti VS, Hernandez K, Neill D. Differences between weekend and weekday nurse work environments and patient outcomes: a focus group approach to model testing. J Perinat Neonatal Nurs. 2007;21(4):331-41.

26. Pronovost PJ, Angus DC, Dorman T, Robinson KA, Dremsizov TT, Young TL. Physician staffing patterns and clinical outcomes in critically ill patients: a systematic review. JAMA. 2002;288(17):2151-62.

27. Petersen LA, Brennan TA, O'Neil AC, Cook EF, Lee TH. Does housestaff discontinuity of care increase the risk for preventable adverse events? Ann Intern Med. 1994;121(11):866-72.

28. Thorpe KE. House staff supervision and working hours. implications of regulatory change in New York State. JAMA. 1990;263(23):3177-81.

29. Arora V, Johnson J, Lovinger D, Humphrey HJ, Meltzer Do. Communication failures in patient sign-out and suggestions for improvement: a critical incident analysis. Qual Saf Health Care. 2005; 14(6):401-7.

30. Horwitz LI, Moin T, Krumholz HM, Wang L, Bradley EH. Consequences of inadequate sign-out for patient care. Arch Intern Med. 2008; 168(16): 1755-60.

31. Kazley AS, Hillman DG, Johnston KC, Simpson KN. Hospital care for patients experiencing weekend vs weekday stroke: a comparison of quality and aggressiveness of care. Arch Neurol. 2010;67(1):39-44.

32. Rothschild JM, Bates DW, Franz C, Soukup JR, Kaushal R. The costs and savings associated with prevention of adverse events by critical care nurses. J Crit Care. 2009;24(3):471.e1-e7.

33. McGillis Hall L, Doran D, Pink GH. Nurse staffing models, nursing hours, and patient safety outcomes. J Nurs Adm. 2004;34(1):41-5.

34. Cho SH, Ketefian S, Barkauskas VH, Smith DG. The effects of nurse staffing on adverse events, morbidity, mortality, and medical costs. Nurs Res. 2003;52(2):71-9.

35. Dimick JB, Swoboda SM, Pronovost PJ, Lipsett PA. Effect of nurseto-patient ratio in the intensive care unit on pulmonary complications and resource use after hepatectomy. Am J Crit Care. 2001;10 (6):376-82

36. Amaravadi RK, Dimick JB, Pronovost PJ, Lipsett PA. ICU nurse-topatient ratio is associated with complications and resource use after esophagectomy. Intensive Care Med. 2000;26(12):1857-62.

37. McCue M, Mark BA, Harless DW. Nurse staffing, quality, and financial performance. J Health Care Finance. 2003;29(4):54-76. 